\title{
PESTYN PERUNAN SÄILYVYYS NEULAREI'ITETYSSÄ MUOVISSA
}

\author{
Anita Ellala, Lasse Vanhanen ja Rakel Kurkela \\ Elintarvikekemian ja -teknologian laitos, Helsingin yliopisto
}

Saapunut 26.1.1970

Kuluttajapakkauksissa myytävänä oleva peruna on tähän asti ollut valtaosalta multaista tai harjaamalla puhdistettua. Pestynä markkinoitava peruna edustaa multaisen perunamateriaalin ensimmäistä jalostusastetta, jonka etuina on mm. se, että kotitalouksissa hankala pesu jää pois ja että peruna on helpommin nähtävissä ja sen kunto arvioitavissa pakkauksessa.

Siirtyminen pestyn perunan markkinointiin on ollut meillä suhteellisen vähäistä. Tähän on ollut syynä mm. epätietoisuus pestyn perunan kysynnästä, säilyvyydestä sekä siitä, mikä olisi sopiva pakkausmateriaali.

Suurissa tuottajamaissa suoritetut tutkimukset osoittavat, että pestyn perunan varastointikestävyys on yhtä hyvä kuin multaisen perunan edellyttäen, että materiaali on varastoinnin alkaessa täysin tuleentunutta, tervettä ja kuivaa (WAGgoner 1956, SwAN 1956, Perry 1953a). Saastuneessa materiaalissa tapahtuu pesun yhteydessä mikrobien leviämistä, mikä aiheuttaa myöhemmin pilaantumista pestyssä perunassa, joten sen markkinoinnissa on käytettävä erittäin korkealaatuisia raaka-aineita. Suoritetut kuluttajatutkimukset ja vuosittain lisääntyvä pestyn perunan osuus tuoreen perunan myynnissä osoittavat, että kuluttajat ovat hyväksyneet tuotteen ja halukkaasti siirtyvät sen käyttöön (Perry 1953a, Perry ja Merchant 1951, Die Niederländische Kartoffel 1968, Smith 1968).

Pestyn perunan tarpeellinen säilymisaika pakattuna on noin $2-3$ viikkoa eli aika, mikä kuluu pakkaukseen, kuljetukseen ja vähittäismyyntiin. Pakkaukseen käytettävältä materiaalilta on siten vaadittava, että se säilyttää perunan moitteettomana vähintään tämän ajan.

Perinteellisesti on perunan pakkaukseen käytetty Suomessa voimapaperia, jossa perunan tiedetään säilyvän hyvin. Teollisuus on kuitenkin kiinnostunut mahdollisuudesta käyttää muovia perunan pakkausmateriaalina, koska pakkaus on tällöin automatisoitavissa ja tulee siten voimapaperipakkausta huomattavasti halvemmaksi (LATVALA, julkaisematon tieto v. 1969). 
Suoritetut esivarastointikokeet osoittivat, että pestyn perunan säilyvyysaika muovipakkauksissa oli selvästi lyhyempi kuin jakeluun tarvittava aika (2-3 viikkoa), kun sensijaan paperipakkauksissa perunat yleensä säilyivät pilaantumattomina tämän ajan. Olennainen ero muovikalvon ja paperin välillä oli kaasujen läpäisevyydessä. Samoissa tutkimuksissa kokeiltiin, missä määrin pestyn perunan säilyvyys parani lisättäessä rei'ityksellä muovin kaasujen läpäis evyyttä. Käytetty rei'itys $\left(Ø 3 \mathrm{~mm} / 100 \mathrm{~cm}^{2}\right)$ oli kuitenkin niin harva, että yksityisten mukuloiden painautuessa kalvoa vasten reijät tukkeutuivat ja täten rei'ityksen vaikutus jäi käytännössä tehottomaksi. Tämän vuoksi tutkittiin pestyn perunan säilyvyys erittäin tiheästi rei'itetyssä n.s. neularei'itetyssä muovissa.

\section{Materiaali ja menetelmät}

Pakkausmateriaalina olivat kokeessa

LD-polyeteeni, läpinäkyvä, paksuus $0.05 \mathrm{~mm}$ (Wi-pakkaus, Wihuri-Yhtymä Oy)

" läpinäkyvä, paksuus $0.05 \mathrm{~mm}$, $3 \mathrm{~mm}: \mathrm{n}$ reikä/20 cm² (Upo Oy)

" musta neularei'itetty, reikien etäisyys $12 \mathrm{~mm}$ ja $0.1 \mathrm{~mm}$ (Upo Oy)

ja voimapaperi, $80 \mathrm{~g} / \mathrm{cm}^{2}$ (Rosenlew Oy)

Polyeteenipakkausten koko oli: korkeus $25 \mathrm{~cm}$, leveys $28 \mathrm{~cm}$ ja paksuus $8-10 \mathrm{~cm}$ ja voimapaperipakkauksen $28 \mathrm{~cm} \times 19 \mathrm{~cm} \times 12-15 \mathrm{~cm}$.

Perunamateriaali saatiin Itä-Suomen Raakasokeritehdas Oy:n kesän 1968 kenttäkokeista ja talousviljelyksiltä. Kokeissa olivat mukana lajikkeet Alfa, Bintje, Realta, Rekord, Patrones ja Sirtema. Nämä kenttäkokeissa olleet lajikkeet oli viljelty virustestatusta siemenestä samalla kasvupaikalla kahdella eri lannoitustasolla (MÄKI 1968):

1. normaali lannoitustaso: $75 \mathrm{~kg} \mathrm{~N} / \mathrm{ha}, 200 \mathrm{~kg} \mathrm{~K}_{2} \mathrm{O} / \mathrm{ha}$, $190 \mathrm{~kg} \mathrm{P}_{2} \mathrm{O}_{5} / \mathrm{ha}$

2. voimakas lannoitustaso: $150 \mathrm{~kg} \mathrm{~N} / \mathrm{ha}, 400 \mathrm{~kg} \mathrm{~K}_{2} \mathrm{O} / \mathrm{ha}$, $380 \mathrm{~kg} \mathrm{P}_{2} \mathrm{O}_{5} / \mathrm{ha}$.

Siemenen laadun vaikutusta perunan säilymiseen pestynä tutkittiin Realta-lajikkeella, jota oli kahdesta erilaisesta siemenestä viljellyt erät: toinen virustestatusta (kenttäkokeista) ja toinen tautisesta, huonolaatuisesta siemenestä (talousviljelyksiltä). Molemmat oli lannoitettu ed. m. normaalilla lannoituksella.

Pesu, kuivaus ja varastointi. Perunat pestiin rumpupesukoneella (MKT-tehtaat Oy, Helsinki) 5 min. ajan ja annettiin kuivua huoneenlämpötilassa 1.5-2 tuntia ennen pakkausta, jolloin ne olivat pinnaltaan kuivia. Pakkauksessa oli n. $2 \mathrm{~kg}$ perunaa. Perunat varastoitiin seuraavissa olosuhteissa:

$\begin{array}{rc}\text { lämpötila } & \text { suhteellinen kosteus } \\ 4-6{ }^{\circ} \mathrm{C} & 80-85 \% \\ 10^{\circ} \mathrm{C} & 65-75 \% \\ 22^{\circ} \mathrm{C} & 40-60 \%\end{array}$

4-6 ${ }^{\circ} \mathrm{C}: \mathrm{n}$ ja $10^{\circ} \mathrm{C}: \mathrm{n}$ varastot olivat pimeitä ja olosuhteet vastasivat jäähdytystiloissa varastointia. $22{ }^{\circ} \mathrm{C}$ :n varasto oli valoisa, mutta näytteet oli suojattu suoranaiselta auringonvalolta. Tämä varasto vastasi myymäläolosuhteita ilman loistelamppuvalaistusta. Vihertymisestä loistelamppuvalaistuksessa selostetaan tuonnempana. 
Perunoiden säilyminen arvosteltiin varastoinnin aikana ulkonaisen pilaantumisen sekä maun ja jauhoisuuden perusteella.

Ulkonainen pilaantuminen arvosteltiin laskemalla pakkauksesta homehtuneiden ja mädäntyneiden mukuloiden prosentuaalinen osuus. Pakkaukset tarkastettiin viikoittain.

Pestyn perunan säilymistä mitattiin kahdella tavalla:

a) määrittämällä viikoittain triangelitestillä aika, jonka perunat säilyivät maultaan ja jauhoisuudeltaan yhtä hyvänä kuin multaisena $4-6{ }^{\circ} \mathrm{C}$ :ssa varastoidut perunat,

b) määrittämällä ruokaperunakelpoisuus maun ja jauhoisuuden arvostelun perusteella.

Maun ja jauhoisuuden arvostelua varten perunat lajiteltiin suolaliuoksilla viiteen eri ominaispainoluokkaan ( $<1.065,1.065-1.075,1.075-1.085,1.085-1.095,>1.095)$. Arvostelussa käytettiin sitä ominaispainoluokkaa, jota k.o. näytteessä oli painomäärältään eniten. Arvostelua varten perunat kuorittiin ja keitettiin kypsiksi höyryssä $30-35$ minuuttia. Kypsyys todettiin haarukalla kokeilemalla. Triangelitestissä näytteet annettiin soseena, joka valmistettiin hienontamalla höyryssä keitetyt perunat pusertimella. Ruokaperunakelpoisuus arvosteltiin kokonaisesta perunasta. Näytteet annettiin arvostelijoille arvotussa järjestyksessä. Arvostelun suoritti $6-8$ harjaantunutta maistajaa yksittäisissä arvostelukopeissa. Kerrallaan oli arvosteltavana kuusi näytettä: kaksi triangelitestiä tai kuusi yksittäistä näytettä maun ja jauhoisuuden arvostelussa. Arvostelu tapahtui aamupäivisin klo 11 .

Ruokaperunan maun ja jauhoisuuden arvostelussa käytetty lomake.

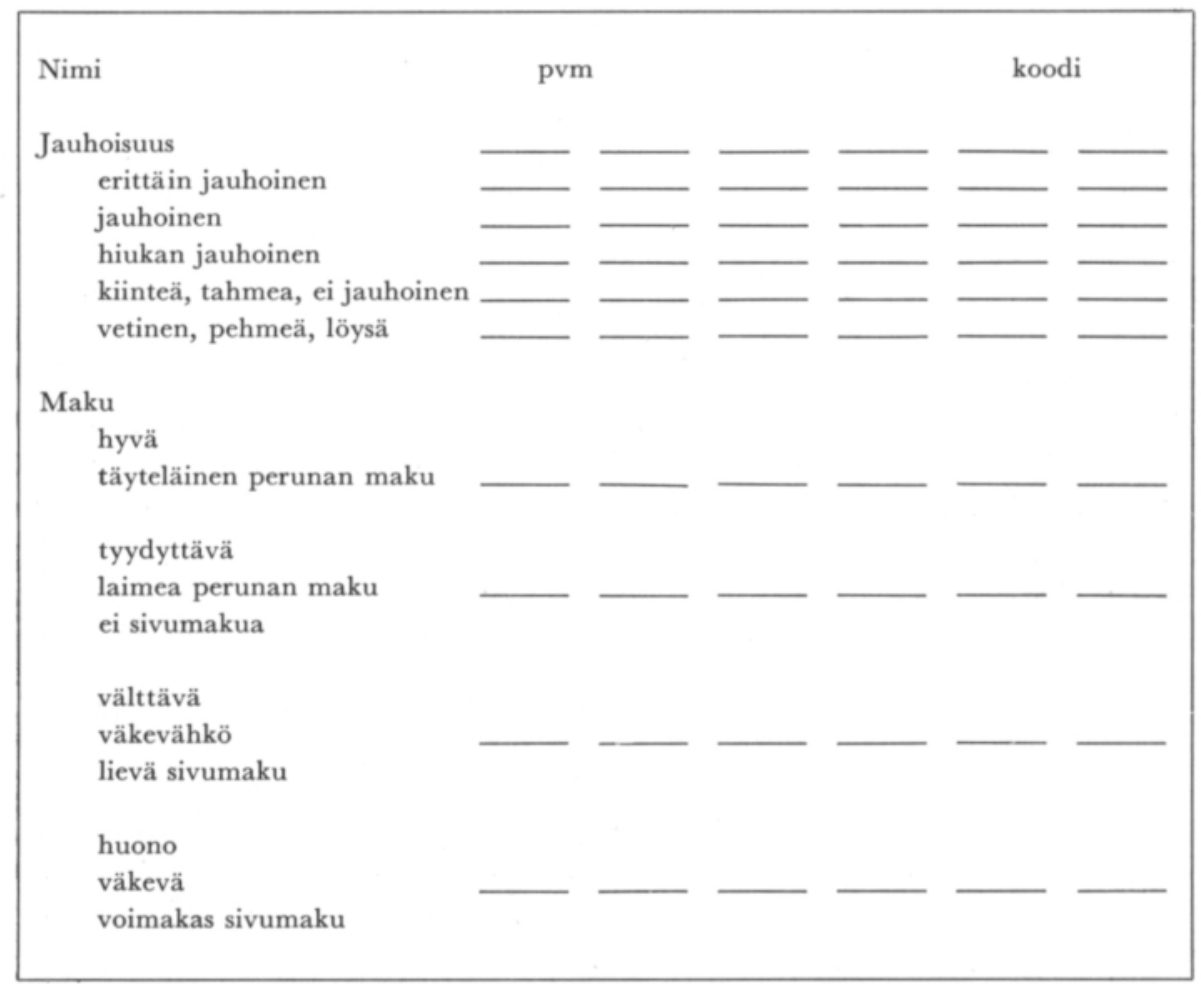


Jauhoisuuden arvostelussa käytettiin Lugt'n menetelmästä muunnettua asteikkoa (Lugt ja Goodijk 1959):

— erittäin jauhoinen

- jauhoinen

- hiukan jauhoinen

— kiinteä, tahmea, ei jauhoinen

- vetinen, pehmeä.

Arvostelussa käytetty lomake on esitetty oheisena asetelmassa. Tulosten laskemista varten annettiin kullekin jauhoisuusasteelle pisteet seuraavasti: erittäin jauhoinen 4, jauhoinen 3, hiukan jauhoinen 2.5, kiinteä, tahmea 2 ja vetinen, pehmeä 1. Jauhoisuudeltaan moitteettomana pidettävän näytteen oli oltava vähintään hiukan jauhoinen ts. sen jauhoisuudesta saaman pistemäärän tuli olla vähintään 2.5 .

Maun arvostelussa käytettiin asteikkoa:

- hyvä, täyteläinen perunan maku, ei sivumakua

— tyydyttävä, laimea perunan maku, ei sivumakua

— välttävä, väkevähkö, lievä sivumaku

— huono, väkevä, voimakas sivumaku

Samoin kuin jauhoisuuden arvostelussa (oheinen asetelma) annettiin tulosten laskemista varten pisteet kullekin makuasteelle seuraavasti: hyvä 4 , tyydyttävä 3 , välttävä 2 ja huono 1. Maultaan moitteettomana pidettiin näytettä, joka sai arvostelussa keskiarvoksi $\geqq 2.5$ pistettä.

Vihertymisen tutkimista varten perunat pakattiin ja varastoitiin huoneenlämpötilassa loistelamppuvalaistuksessa. Valolähteenä olivat $40 \mathrm{~W}: \mathrm{n}$ lamput $(2 \mathrm{kpl}) 2 \mathrm{~m}: \mathrm{n}$ etäisyydellä perunoista.

Pakkauksissa oli perunoita yhden kerroksen paksuudelta, n. 20 kpl. Jokaisesta pakkausmateriaalityypistä oli kymmenen näytettä. Perunoiden arvostelu suoritettiin 1 vrk:n välein laskemalla vihertyneiden määrä kahdesta näytepakkauksesta. Vihertymisen havaitsemisen helpottamiseksi perunat kuorittiin kevyesti (1 min) karborundum-kuorimakoneella (Sama S 8, Metalliteos, Helsinki).

Kondenssiveden kerääntymisen tutkimiseksi pakkaukset siirrettiin huoneenlämpötilasta $\left(22^{\circ} \mathrm{C}\right) 4-6{ }^{\circ} \mathrm{C}: n$ varastoon ja päinvastoin vuorokauden väliajoin. Veden kondensoituminen pussissa todettiin silmävaraisesti.

Pakkausmateriaalien hiilidioksidin läpäisevyydet tutkittiin määrittämällä kalvon läpi diffundoituneen hiilidioksidin saostaman bariumkarbonaatin määrä. Bariumhydroksidiliuosta mitattiin (10 ml 0.1-n) dekanterilaseihin $(50 \mathrm{ml})$. Lasit peitettiin tutkittavana olevilla kalvoilla ja pidettiin huoneen lämpötilassa. Kalvon läpi diffundoitunut hiilidioksidi saostaa bariumin karbonaattina. Jäljelle jäänyt bariumhydroksidi titrattiin laimealla suolahapolla ja laskettiin vastaava diffundoituneen hiilidioksidin määrä. Titraukset tehtiin 6 tunnin aikana 2 tunnin välein.

Kalvojen vesihöyryn läpäisevyys määritettiin gravimetrisesti. Punnituslasin pohjalle levitettiin kuivattua $\mathrm{CaCl}_{2}: \mathrm{a}(10 \mathrm{~g})$, lasit peitettiin tutkittavana olevilla kalvoilla ja asetettiin eksikaattoriin, jossa vallitsi $100 \%$ suhteellinen kosteus. Vesihöyryn imeytymistä kalsiumkloridiin seurattiin 1 vrk:n välein tehtyjen punnitusten avulla. Tulokset laskettiin $\%$ :na voimapaperin vastaavista arvoista. 
Pakkausmateriaalien valonläpäisevyyttä mitattiin Perkin Elmer DU 137 spektrofotometrillä. Mittaus suoritettiin aallonpituudella 210-750 m $\mu$ ilmaa vastaan, jonka transmissiota merkittiin $\mathrm{T}=100$.

\section{Kokeet ja tulokset}

S ä i l y v y s k o ke e t. Tutkimuksen aikana suoritettiin syksyllä 1968 ja keväällä 1969 yhteensä viisi eri säilyvyyskoetta, joiden järjestelyt käyvät selville taulukosta 1. Kokeissa olivat perunalajikkeet Alfa, Bintje, Patrones, Realta, Rekord ja Sirtema. Ensimmäisessä varastointikokeessa oli pakkausmateriaalina myös läpinäkyvä polyeteeni, mutta perunoiden herkästi tapahtuvan vihertymisen vuoksi käytettiin myöhemmissä kokeissa ainoastaan mustaa neularei'itettyä polyeteeniä.

Ulkonaisen pilaantumisen esiintymistä tarkkailtiin kaikista kokeissa olleista näytteistä. Painohäviöt määritettiin 3 viikkoa varastoinnin jälkeen $22^{\circ} \mathrm{C}$ :ssa ja $10^{\circ} \mathrm{C}$ :ssa (kokeet $2-3)$.

Pestyn perunan säilymistä multaisen perunan veroisena polyeteeniin pakattuna $10^{\circ} \mathrm{C}$ :ssa ja $22{ }^{\circ} \mathrm{C}$ :ssa tutkittiin viikoittain suoritetuilla triangelitesteillä käyttäen vertailumateriaalina $4-6{ }^{\circ} \mathrm{C}$ :sta $85 \% \mathrm{rH}$ :ssa multaisena vapaasti varastoitua perunaa (kokeet $1-3)$.

Ruokaperunakelpoisuus arvosteltiin $22^{\circ} \mathrm{C}$ :ssa varastoidusta näytteestä viikko sen jälkeen, kun triangelitestit olivat osoittaneet maun ja jauhoisuuden muuttuneen multaiseen perunaan verrattuna (koe 2).

Lannoituksen vaikutusta pestyn perunan säilymiseen tutkittiin määrittämällä ruokaperunakelpoisuus normaalilla ja voimakkaalla lannoituksella viljellyistä perunoista varastoitaessa $10{ }^{\circ} \mathrm{C}$ :ssa (kokeet 3 ja 4). Pakkausmateriaaleina olivat musta, neularei'itetty polyeteeni ja voimapaperi.

Siemenen vaikutusta pestyn perunan varastointikestävyyteen tutkittiin Realta-lajikkeella (koe 5).

Säilyvyyskokeet osoittivat, että kaikki kokeissa olleet virustestatusta, taudittomasta siemenestä viljellyt pestyn perunan näytteet säilyivät ulkonaisesti pila a t um a t t o m i n a sekä voimapaperiin että polyeteeniin pakattuna koko kokeiden ajan; huoneenlämpötilassakin jopa seitsemän viikkoa.

Painohäviöiden mittaamisessa saadut tulokset olivat seuraavat:

$\begin{array}{lll} & 22{ }^{\circ} \mathrm{C} & 10{ }^{\circ} \mathrm{C} \\ \text { voimapaperi } & 5.4 \% & 3.1 \% \\ \text { neularei'itetty polyeteeni } & 4.1 \% & 2.7 \%\end{array}$

Tulokset osoittavat, että 3 viikon $22^{\circ} \mathrm{C}$ :ssa varastoinnin aikana oli painohäviö neularei'itetyssä polyeteenissä $4.1 \%$ ja voimapaperipakkauksessa $5.4 \%$. Alhaisemmassa varastointilämpötilassa $\left(10^{\circ} \mathrm{C}\right)$ olivat painohäviöt pienemmät; neularei'itetyssä polyeteenissä $2.7 \%$ ja voimapaperipakkauksissa $3.1 \%$.

Tulokset kokeista, joissa tutkittiin, kauanko pesty peruna säilyy multaisen perunan veroisena, olivat seuraavat: 


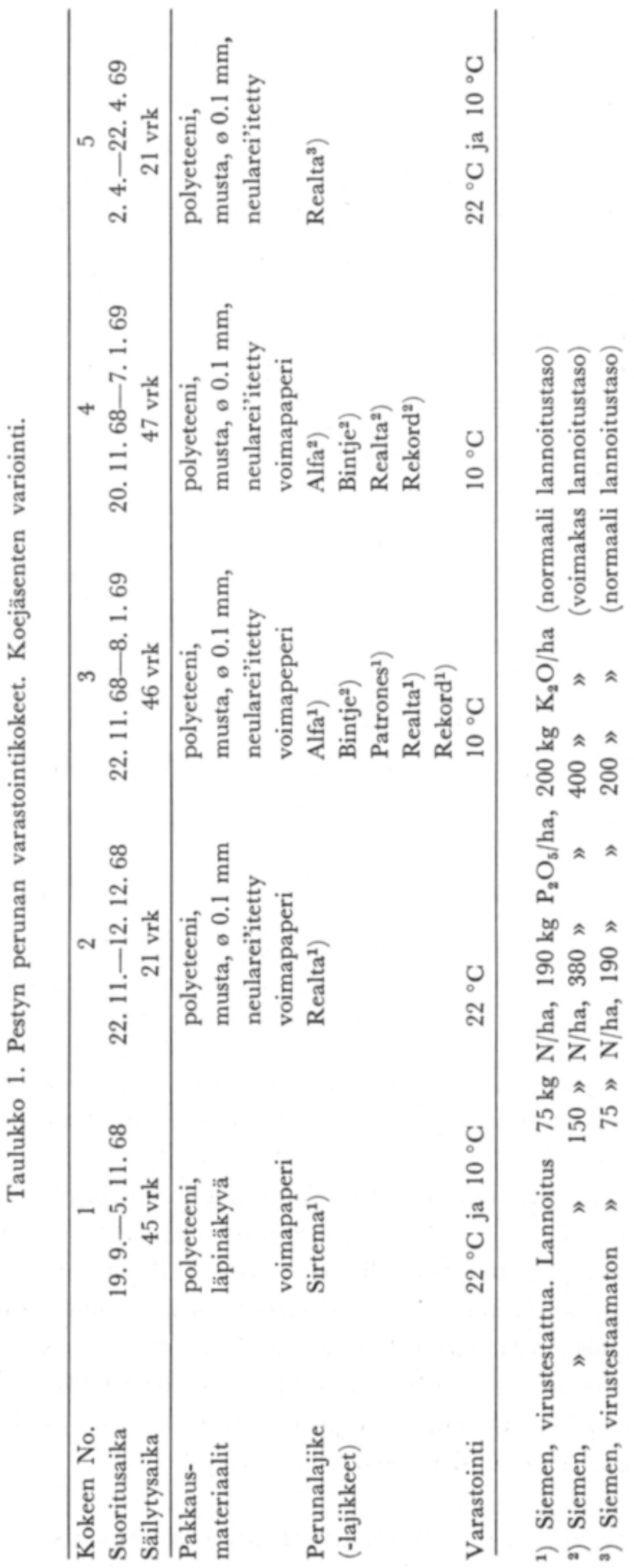




$\begin{array}{lcc}\text { perunalajike } & \begin{array}{c}\text { säilymisaika multaisen perunan } \\ \text { veroisena vk }\end{array} \\ & 10^{\circ} \mathrm{C} & 22{ }^{\circ} \mathrm{C} \\ \text { Sirtema } & 3 & \\ \text { Bintje } & 3 & 2 \\ \text { Realta } & 3 & 2\end{array}$

Tulokset osoittavat, että $10^{\circ} \mathrm{C}$ :ssa polyeteeniin pakattuna olleet Sirtema ja Bintje säilyivät 3 viikkoa ja $22^{\circ} \mathrm{C}$ :ssa varastoitu Realta säilyi 2 viikkoa multaisen perunan veroisena. Mainittujen aikojen jälkeen perunat poikkesivat multaisena $4-6{ }^{\circ} \mathrm{C}$ :ssa varastoiduista perunoista heikomman jauhoisuuden ja tunkkaisen maun perusteella. Realtasta tehdyn ruokaperunakelpoisuuden arvostelun tulokset on esitetty taulukossa 2. Tulokset osoittavat, että perunat olivat ruokaperunaksi kelvollisia vielä 3 viikon $22^{\circ} \mathrm{C}$ :ssa varastoinnin jälkeen, sekä neularei'itetyssä polyeteenissä että voimapaperissa, vaikka jauhoisuus olikin alentunut molemmissa pakkauksissa multaiseen perunaan verrattuna (taulukko 2).

Taulukko 2. Pestynä varastoidun perunan (Realta) ruokaperunakelpoisuus. Näytteitä säilytetty 21 vrk huoneenlämpötilassa. Hyväksyttävyysraja 2.5 p.

\begin{tabular}{llll}
\hline Näyte & Jauhoisuus & Maku \\
\hline Polyeteenipakkaus, musta, neularei'itetty & $\overline{\mathrm{X}}$ & 2.5 & 2.9 \\
& $\mathrm{~S} \overline{\mathrm{x}}$ & 0.15 & 0.23 \\
& $\overline{\mathrm{x}}$ & 2.6 & 3.0 \\
Voimapaperipakkaus & $\mathrm{S} \overline{\mathrm{x}}$ & 0.10 & 0.15 \\
& & & \\
& & 3.0 & 2.9 \\
$4-6{ }^{\circ} \mathrm{C}:$ ssa multaisena varastoitu peruna & $\overline{\mathrm{X}}$ & 0.15 & 0.31 \\
& $\mathrm{~S} \overline{\mathrm{x}}$ & & \\
\hline
\end{tabular}

Lannoituksen vaikutus pestyn perunan ruokaperunakelpoisuuden säilymiseen käy selville taulukoista 3 ja 4 . Tulokset osoittavat, että normaalin lannoitustason näytteet Alfa ja Rekord säilyvät jopa 7 viikkoa $10^{\circ} \mathrm{C}$ :ssa sekä neularei'itettyyn polyeteeniin että voimapaperiin pakattuna ruokaperunaominaisuuksiltaan moitteettomina, kun taas voimakkaan lannoitustason näytteet eivät 3 viikon varastoinnin jälkeen vastaavissa olosuhteissa täyttäneet kaikissa suhteissa moitteettomalle ruokaperunalle asetettuja vaatimuksia. Maku arvosteltiin voimakkaan lannoitustason näytteistä raja-arvona ollutta 2.5 pistettä huonommaksi voimapaperipakkauksissa lajikkeista Alfa, Realta ja Rekord ja polyeteenipakkauksissa lajikkeista Bintje ja Rekord. Jauhoisuus arvosteltiin sekä voimapaperi- että polyeteenipakkauksissa olleista Bintjestä ja Realtasta huonommaksi kuin »hiukan jauhoinen», joka jauhoisuuden osalta asetettiin alarajaksi moitteettomalle ruokaperunalle (taulukko 4).

Siemenen laadun vaikutusta tutkittaessa osoittautui, että huonolaatuisesta siemenestä viljelty Realta pilaantui nopeasti. Kolmen viikon varastoinnin aikana $22{ }^{\circ} \mathrm{C}$ :ssa oli pilaantuneita mukuloita $10 \%$ ja $10{ }^{\circ} \mathrm{C}$ :n varastossa $1-5 \%$ pakkauksen painosta, kun sen sijaan 
Taulukko 3. Pestyn perunan (Alfa ja Rekord) ruokaperunakelpoisuus 7 viikon $10^{\circ} \mathrm{C}: s s a$ varastoinnin jälkeen. Molemmat lajikkeet saaneet normaalin lannoituksen. Hyväksyttävyysraja $2.5 \mathrm{p}$.

\begin{tabular}{|c|c|c|c|c|c|}
\hline \multirow{2}{*}{ Näyte } & & \multicolumn{2}{|c|}{ Alfa } & \multicolumn{2}{|c|}{ Rekord } \\
\hline & & Jauhoisuus & Maku & Jauhoisuus & Maku \\
\hline \multirow[t]{2}{*}{ Polyeteeni, musta, neularei'itetty } & $\overline{\mathrm{x}}$ & 2.8 & 2.5 & 3.2 & 2.6 \\
\hline & $\mathrm{S} \overline{\mathrm{x}}$ & 0.09 & 0.38 & 0.23 & 0.18 \\
\hline \multirow[t]{2}{*}{ Voimapaperi } & $\overline{\mathrm{x}}$ & 2.7 & 3.0 & 3.3 & 2.9 \\
\hline & $\mathrm{S}_{\overline{\mathrm{x}}}$ & 0.13 & 0.19 & 0.23 & 0.39 \\
\hline \multirow{2}{*}{\multicolumn{2}{|c|}{$\begin{array}{l}4-6^{\circ} \mathrm{C} \text { :ssa multaisena varastoitu } \overline{\mathrm{X}} \\
\text { (vertailunäyte) }\end{array}$}} & 3.4 & 2.8 & 3.3 & 2.9 \\
\hline & $\mathrm{S}_{\mathbf{x}}$ & 0.27 & 0.20 & 0.18 & 0.34 \\
\hline
\end{tabular}

Taulukko 4. Pestyn perunan (Alfa, Bintje, Realta ja Rekord) ruokaperunakelpoisuus 3 viikon $10^{\circ} \mathrm{C}: s s a$ varastoinnin jälkeen. Kaikki lajikkeet saaneet voimakkaan lannoituksen. Hyväksyttävyysraja 2.5 p.

\begin{tabular}{|c|c|c|c|c|c|c|c|c|c|}
\hline \multirow{2}{*}{ Näyte } & & \multicolumn{2}{|c|}{ Alfa } & \multicolumn{2}{|c|}{ Bintje } & \multicolumn{2}{|c|}{ Realta } & \multicolumn{2}{|c|}{ Rekord } \\
\hline & & Jauhois. & Maku & Jauhois. & Maku & Jauhois. & Maku & Jauhois. & Maku \\
\hline \multirow[t]{2}{*}{$\begin{array}{l}\text { Polyeteeni, must } \\
\text { neularei'itetty }\end{array}$} & $\overline{\mathrm{x}}$ & 2.8 & 2.8 & 2.1 & 2.3 & 2.3 & 2.7 & 2.9 & 2.0 \\
\hline & $\mathrm{S} \overline{\mathbf{x}}$ & 0.11 & 0.31 & 0.13 & 0.27 & 0.17 & 0.21 & 0.07 & 0.31 \\
\hline \multirow[t]{2}{*}{ Voimapaperi } & $\overline{\mathrm{x}}$ & 2.7 & 2.3 & 2.2 & 2.6 & 2.1 & 2.3 & 2.8 & 2.3 \\
\hline & $\mathrm{S} \overline{\mathrm{x}}$ & 0.17 & 0.33 & 0.11 & 0.29 & 0.27 & 0.17 & 0.10 & 0.27 \\
\hline \multicolumn{10}{|c|}{$4-6^{\circ} \mathrm{C}$ :ssa multaisena } \\
\hline varastoitu & $\overline{\mathrm{x}}$ & 2.7 & 2.5 & 2.8 & 3.0 & 2.4 & 2.5 & 2.7 & 2.8 \\
\hline (vertailunäyte) & $\mathrm{S} \overline{\mathrm{x}}$ & 0.21 & 0.40 & 0.10 & 0.22 & 0.08 & 0.34 & 0.20 & 0.37 \\
\hline
\end{tabular}

virustestatusta siemenestä viljelty Realta säilyi pilaantumattomana koko kokeiden suoritusajan.

V i h e r t y m is k o k e e t. Kokeissa tutkittiin perunoiden vihertyminen loistelamppuvalaistuksessa voimapaperipussissa, sekä läpinäkyvässä ja mustassa neularei’itetyssä polyeteenipakkauksessa.

Kokeet osoittivat, että läpinäkyvässä polyeteenissä perunat vihertyivät jo 2 vrk:n aikana. Viiden vrk:n varastoinnin jälkeen oli eri pakkauksissa vihertyneitä mukuloita seuraavat määrät:
musta, neularei'itetty polyeteeni, $。 0.1 \mathrm{~mm}$
voimapaperi
läpinäkyvä polyeteeni
$25 \%$
$50 \%$
$100 \%$

vihertyneitä

Kondenssiveden muodostuminen. Kokeissa verrattiin kondenssiveden muodostumista rei'ittämättömässä ja neularei'itetyssä muovipakkauksessa, kun 
pakkauksia siirrettiin $22{ }^{\circ} \mathrm{C}$ :n varastosta $4-6{ }^{\circ} \mathrm{C}$ :een ja päinvastoin 1 vrk välein. Kokeet osoittivat, että neularei'itettyihin polyeteenipakkauksiin ei kondenssivettä synny varaston lämpötilojen muutosten yhteydessä. Vastaavissa olosuhteissa rei'ittämättömään polyeteenipussiin muodostui runsaasti vettä pakkauksen sisäpintaan.

Pakkausmateriaalien hilidioksidin ja vesihöyryn läpäis evyydet. Hiilidioksidin läpäisevyys oli rei'ittämättömällä polyeteenillä $16 \%, 0.1$ mm:n reikiä sisältävällä kalvolla $32 \%$ ja $0.3 \mathrm{~mm}: n$ reikiä sisältävällä kalvolla $67 \%$ vastaavasta voimapaperin arvosta (taulukko 5). Vesihöyryn läpäisevyys oli rei'ittämättömällä polyeteenikalvolla $8 \%$ ja neularei'itetyillä kalvoilla 16 ja $26 \%$ vastaavista voimapaperin arvoista. Polyeteenissä, jossa oli $3 \mathrm{~mm}: n$ reikä $20 \mathrm{~cm}^{2}$ kohti, oli hiilidioksidin läpäisevyys $55 \%$ vastaavasta voimapaperin arvosta (taulukko 5).

Taulukko 5. Hiilidioksidin ja vesihöyryn diffuusio eri pakkausmateriaalikalvojen läpi ilmoitettuna suhteellisina arvoina. Voimapaperin hiilidioksidin ja vesihöyryn läpäisevyydelle on annettu suhdeluku 100.

\begin{tabular}{lcc}
\hline Pakkausmateriaali & $\begin{array}{c}\text { Hiilidioksidin } \\
\text { läpäisevyys }\end{array}$ & $\begin{array}{c}\text { Vesihöyryn } \\
\text { läpäisevyys }\end{array}$ \\
\hline Voimapaperi & 100 & 100 \\
Rei'ittämätön polyeteeni & 16 & 8 \\
Neularei'itetty polyeteeni, $0.1 \mathrm{~mm}$ & 32 & 16 \\
Neularei'itetty polyeteeni, ø $0.3 \mathrm{~mm}$ & 67 & 26 \\
Polyeteeni, jossa on $3 \mathrm{~mm}$ ๑ reikä/20 cm² & 55 & - \\
\hline
\end{tabular}

Taulukko 6. Läpinäkyvän ja mustan polyeteenikalvon sekä voimapaperin valonläpäisevyys. Taulukossa ilmoitettu kalvojen transmissio, kun ilman $T=100$.

\begin{tabular}{cccc}
\hline $\begin{array}{c}\text { Aallonpituus } \\
\mathrm{m} \mu\end{array}$ & $\begin{array}{c}\text { Kirkas } \\
\text { polyeteeni }\end{array}$ & $\begin{array}{c}\text { Musta } \\
\text { polyeteeni }\end{array}$ & Voimapaperi \\
\hline 210 & 8.6 & 0.0 & 0.0 \\
250 & 30.5 & 0.0 & 0.0 \\
290 & 49.5 & 0.0 & 0.0 \\
330 & 63.0 & 0.0 & 0.0 \\
& & & \\
370 & 70.0 & 0.03 & 0.04 \\
410 & 72.0 & 0.05 & 0.14 \\
450 & 75.0 & 0.07 & 0.19 \\
490 & 77.0 & 0.09 & 0.23 \\
& & & \\
530 & 78.0 & 0.14 & 0.30 \\
570 & 80.0 & 0.19 & 0.38 \\
& & & \\
610 & 82.0 & 0.26 & 0.47 \\
650 & 84.0 & 0.33 & 0.55 \\
690 & 85.0 & 0.42 & 0.62 \\
& & & \\
730 & 86.0 & 0.53 & 0.68 \\
750 & 87.0 & 0.60 & 0.76 \\
\hline
\end{tabular}


Pakkausmateria a lin valon läpä is evy ys. Läpinäkyvän ja mustan polyeteenin sekä voimapaperin valonläpäisevyysarvot on esitetty taulukossa 6 aallonpituusalueella $200-750 \mathrm{~m} \mu$. Klorofyllin synteesi tapahtuu voimakkaasti kahdella aallonpituusalueella 400 - $500 \mathrm{~m} \mu$ (maksimi $450 \mathrm{~m} \mu$ ) ja 600-750 m $\mu$ (maksimi $655 \mathrm{~m} \mu$ ) (MPELKAs). Kirkkaan muovin valonläpäisyn transmissioarvo oli näillä alueilla $70-77$ ja $82-85$. Mustan polyeteenin vastaavat arvot olivat $0.03-0.09,0.26-0.42$ ja voimapaperin $0.04-$ $0.23,0.47-0.62$.

\section{Tulosten tarkastelua}

Erityisenä vaikeutena perunan arvostelussa on samassa, lajikepuhtaassakin koe-erässä vallitseva mukuloiden erilaisuus; mm. mukuloiden kuiva-ainepitoisuuden vaihtelut ovat varsin suuret, ja ne vaikuttavat perunan makuun ja jauhoisuuteen. Tämän vaikutuksen eliminosimieksi on tutkimuksessa käytetty maun ja jauhoisuuden arvostelussa ominaispainolajiteltua materiaalia, jolloin on saatu tasalaatuiset näyte-erät ja niistä luotettavammin esiin esim. varastoinnin aiheuttamat maun ja jauhoisuuden muutokset. Arvostelussa käytətyn painomäärältään suurimman ominaispainoluokan voidaan katsoa edustavan parhaiten kyseisen lajikkeen ruokaperunaominaisuuksia.

Ruokaperunakelpoisuuden arvostelussa käytettiin aluksi menetelmää, jossa maun ja jauhoisuuden arvostelussa on annettu neljä eri vaihtoehtoa. Arvostelijoiden toivomuksesta muunnettiin tätä menetelmää jauhoisuuden osalta ottamalla käyttöön väliaste jauhoisen ja kiinteän-ei-jauhoisen välille, nim. hiukan jauhoinen. Näin haluttiin tarkentaa asteikkoa perunan hyväksyttävyyden kannalta kriittisellä alueella.

Suoritetut varastointikokeet osoittivat, että kaikista tutkituista lajikkeista hyvälaatuisesta siemenestä viljelty peruna säilyi pestynä ulk on a is esti pila a n t u mat t o$\mathrm{m}$ a n a sekä polyeteeniin että voimapaperiin pakattuna useita viikkoja, esim. huoneenlämpötilassakin 7 viikkoa.

Painohäviöiden määrityksessä saadut tulokset osoittivat, että neularei'ityksellä saadaan polyeteenin kaasujen diffuusiota lisätyksi huomattavasti. Esivarastointikokeissa oli todettu, että voimapaperiin pakatuissa perunoissa olivat painohäviöt kuusi kertaa suuremmat kuin umpinaiseen polyeteeniin pakatuissa perunoissa. Neularei'itetyssä muovissa painohäviöt olivat kuitenkin hieman pienemmät kuin voimapaperissa.

Kokeissa saavutettu pestyn perunan säilyminen neularei'itetyssä muovipussissa näyttää riittävältä pestyn perunan markkinoinnin kannalta: pesty peruna säilyi mustassa neularei'itetyssä polyeteenissä 2 viikkoa (Realta) huoneenlämmössä ja 3 viikkoa $10^{\circ} \mathrm{C}$ :ssa samanveroisena kuin multaisena $4-6{ }^{\circ} \mathrm{C}$ :n vapaasti varastoitu peruna.

R uokaperunakelpoisuuden arvostelut osoittivat, että hyvälaatuinen peruna säilyy ruokaperunaominaisuuksiltaan moitteettomana 3 viikon ajan huoneenlämpötilassa ja 7 viikon ajan $10^{\circ} \mathrm{C}$ :ssa sekä voimapaperiin että neularei'itettyyn polyeteeniin pakattuna (kokeet 2 ja 3), huolimatta siitä, että perunan maku ja jauhoisuus huononevat varastoinnin aikana molemmissa pakkauksissa. Maultaan ja jauhoisuudeltaan heikkolaatuisen perunan kelpoisuus ruokaperunana tulee kyseenalaiseksi jo lyhyenkin varastoinnin jälkeen (kokeet 3 ja 4). Pestynä myytäväksi tarkoitetun perunan materiaalin laadulle on siten asetettava erittäin suuret vaatimukset.

Pestyn perunan laatuun vaikuttaviksi tekijöiksi osoittautuivat lannoituksen määrä ja kylvössä käytetyn siemenen laatu. Lannoituksella oli ratkaisevasti vaikutusta mukuloiden 
kuiva-ainepitoisuuden kehittymisessä (MÄKI 1968). Voimakas lannoitus pyrki huonontamaan perunan jauhoisuutta ja makua. Jos perunan mukulat saavat pellossa tai noston yhteydessä tuhosieni- tai mädättäjäbakteeritartunnan, voi niiden säilyvyys olla heikko. Varsinkin noston yhteydessä syntyvät pintaviat ovat otollisia lähtökohtia mikrobien aiheuttamalle pilaantumiselle. Pesun yhteydessä märkävialliset mukulat edelleen saastuttavat terveetkin mukulat; tällä tavoin huono lähtömateriaali aiheuttaa nopeata pilaantumista varastoinnin aikana.

Vihertymiskokeiss a näytteet tutkittiin kevyen kuorinnan jälkeen, jolloin saatiin erittäin nopeasti ja herkästi esiin vihertyneet mukulat. Vihertymisen suhteen tehdyt kokeet osoittivat, että kriittisin vaihe pestyn perunan markkinoinnissa on vähittäiskaupan vaihe, jossa perunat ovat alttiina voimakkaalle loistelamppuvalaistukselle.

Vihertyminen osoittautui täten perunan säilyvyyttä rajoittavaksi tekijäksi kaikissa pakkauksissa pakkauksen joutuessa voimakkaaseen loistelamppuvalaistukseen. Muovin pigmentointi (musta muovi) hidasti kuitenkin vihertymisprosessia. Voimapaperi läpäisi klorofyllin synteesiä katalysoivia valon aallonpituuksia jopa $2-3$ kertaa enemmän kuin musta polyeteeni. Käyttämällä paksumpaa paperia voidaan vihertymistä estää voimapaperipakkauksissa, mutta vastaavasti pakkausmateriaalikustannukset kasvavat.

Suoritetut pakkausmateriaalien vesihöyryn ja hiilidioksidin läpäisevyyksien mittaukset osoittivat, että voimapaperi on parhaiten kaasuja läpäisevä materiaali ja että rei'ityksellä voidaan huomattavasti muuttaa polyeteenin diffuusio-omaisuuksia.

Pestyn perunan säilyvyyden kannalta pakkausmateriaalin vesihöyryn läpäisevyyteen on syytä kiinnittää huomiota kahdesta syystä. Jos pakkaus on täysin umpinainen, tapahtuu pussin sisällä haihtumisen ja soluhengityksen seurauksena vesihöyryn osapaineen nousua yli kyllästymispisteen ja kosteuden tiivistymistä. Tämä luo suotuisat olosuhteet homeiden ja maan muiden mikrobien kasvulle ja jouduttaa pilaantumista. Toisaalta pakkauksen liiallinen ilmavuuskaan ei ole tuotteen säilyvyydelle hyväksi. Jos pakkaukset säilytetään kuivassa huoneilmassa, kuten useimmissa myymälöissä on asianlaita, perunat nahistuvat liiallisen haihtumisen seurauksena. Voimapaperipakkauksessa on haihtuminen todettu kolmen viikon aikana niin runsaaksi, että painohäviö on kohonnut yli viiden prosentin. Tuotteen laadun säilyttämiseksi tällaiset pakkaukset olisi säilytettävä varastoissa, joiden kosteutta voidaan säätää.

Muovimateriaalien hiilidioksidin läpäisevyydet muuttuivat varsin voimakkaasti rei'ityksen suuretessa, mutta olivat ne silti huomattavasti pienempiä kuin voimapaperin diffuusioarvot. Neularei'ityksellä voidaan säädellä siten pakkauksen ilman hiilidioksidipitoisuutta ja sen avulla perunan biologisia toimintoja. Perunan vihertymisen on todettu estyvän, kun perunoita on säilytetty muovipussissa, jossa hiilidioksidipitoisuus on noussut hengityksen vuoksi (Forsyth ja EAves 1968).

\section{rhteenveto}

Sekä mustaan neularei'itettyyn polyeteeniin että voimapaperiin pakattuna ollut hyvälaatuinen pesty peruna säilyi multaisena, $4-6{ }^{\circ} \mathrm{C}$ :ssa varastoidun perunan veroisena kolme viikkoa $10^{\circ} \mathrm{C}$ :ssa ja kaksi viikkoa $22^{\circ} \mathrm{C}$ :ssa. Korkealaatuinen peruna säilyi pestynä $22^{\circ} \mathrm{C}$ :ssa kolme viikkoa ja $10^{\circ}$ :ssa jopa seitsemän viikkoa molemmissa pakkauksissa ruoka- 
perunaominaisuuksiltaan moitteettomana, vaikka se olikin erotettavissa multaisena 4$6{ }^{\circ} \mathrm{C}$ :ssa varastoidusta perunasta. Nämä säilyvyysajat ovat markkinoinnin kannalta riittävät, sillä pakkauksen ja kulutuksen välillä todennäköisesti kuluva aika on noin kaksikolme viikkoa.

Pakattavan perunan laadulla ja kasvukauden aikana vaikuttavilla tekijöillä kuten lannoituksella todettiin olevan ratkaiseva merkitys perunan ruokaperunaominaisuuksien säilymiseen. Jos pakattava perunamateriaali on heikkolaatuista joko virustautisen siemenen tai liian voimakkaan lannoituksen takia, huononee tavaran laatu huomattavasti nopeammin kuin hyvälaatuisen perunan, jopa niin että sen kelpoisuus ruokaperunaksi tulee kyseenalaiseksi lyhyessäkin säilytyksessä pakkauksesta riippumatta.

Tulosten mukaan musta polyeteeni esti parhaiten perunoiden vihertymisen. Vihertyminen osoittautui säilyvyyttä rajoittavaksi tekijäksi, jos perunat joutuivat voimakkaan loistelamppuvalaistuksen alaisiksi.

Vesihöyryn ja hiilidioksidin läpäisevyys oli runsainta voimapaperipakkauksessa. Neularei'ityksellä saatiin polyeteenipakkaus kauttaaltaan kaasuja läpäiseväksi. Vesihöyryn läpäisevyys oli neularei'ityksen ansiosta riittävä; se esti mm. kondenssiveden muodostuksen pakkauksen sisäpintaan varaston lämpötilan muutosten yhteydessä.

\section{KIRJALLISUUS}

Die Niederländische Kartoffel, 1968. Niederländische Auskunftsstelle für Kartoffeln, Den Haag-Holland, Druck Plantijn Rotterdam.

Forsyth, F. R. and Eaves, C. A. 1968. Greening of potatoes, Food Technol. 22: 48-50.

Hardensurg, R. E. 1964. Greening of potatoes during marketing. Amer. Potato Jour. 41: 215-220.

Lugr, C. and Goodijk, G. 1959. Report on the third meeting of the working group "Potato quality research" of EAPR. Versl. I.B.S.O.L. 15: $1-61$.

Mpelkas, C. C. Radiant energy sources for plant growth. Applied Lighting. Bull. 0-278. Commercial Eginenering Dept. Salem. Mass.

MÄKI, EeVA, 1968. Tutkimus teollisuusperunan tuotantomahdollisuuksista Kotkan ympäristössä. Materiaalin tuottamisesta ja kemiallisfysikaalisten laatuominaisuuksien vaihteluista. Pro gradu-kirjoitus. Helsingin Yliopiston elintarvikekemian ja -teknologian laitos. Helsinki.

Perry, A. L. 1953a. Commercial washing of Maine potatoes. Me. Agr. Exp. Sta. Bull. 509.

- — 1953b. Plastic bags for potato packages. Sama Bull. 514.

—-— \& Merchant, C. H. 1951. Consumer acceptance of washed Maine potatoes. Sama Bull. 493.

Sмrт, O. 1968. Potatoes: production, storing, processing. AVI Publ. Comp., Westport, Conn. 06880. Swan, J. D. 1956. Storing washed potatoes. Amer. Potato Jour. 33: 281-284.

WAGGoNeR, P. E. 1956. Washing muddy potatoes. Sama 33: 269-270.

\section{SUMMARY}

KEEPING QUALITY OF WASHED POTATOES IN MICROPERFORATED PLASTIC BAGS

Anita Ellala, Lasse Vanhanen and Rakel Kurkela

Institute of Food Chemistry and Technology, University of Helsinki

The storage life of washed potatoes packed in paper bags and micro-perforated plastic bags was investigated. The potatoes, which were of the varieties Alfa, Bintje, Patrones, Realta, Record and 
Sirtema, were grown in the fields of the Rootsugar Factory of East Finland (Itä-Suomen Raakasokeritehdas Oy, Kotka) in 1968. The effects of fertilizing and illumination were also studied.

The results showed that the storage life of high-quality washed potatoes packed either in paper bags or in pigmented micro-perforated polyethylene bags (distance between holes $12 \mathrm{~mm}$ and diameter of holes $0.1 \mathrm{~mm}$ ) was three weeks at $10{ }^{\circ} \mathrm{C}$ and two weeks at $22{ }^{\circ} \mathrm{C}$. During this time their keeping quality equalled that of the unwashed control material stored at $4{ }^{\circ} \mathrm{C}$. Potatoes kept in these packages under diffuse daylight at $22^{\circ} \mathrm{C}$ were acceptable for food purposes for three weeks, which is sufficient for marketing purposes. The greening of potatoes kept under fluorescence light reduced their storage life. Potatoes of originally low quality, due to heavy fertilization or infected seed, very quickly became unacceptable for food purposes in any kind of package. 